\title{
AGAINST AUTONOMY: WHY PRACTICAL REASON CANNOT BE PURE $^{1}$
}

\author{
JENNIFER A. FREY \\ University of South Carolina \\ Department of Philosophy \\ Byrnes hall Columbia \\ U.S.A \\ frey.jenn@gmail.com
}

\author{
Article info \\ CDD: 142.3 \\ Received: 07.09.2018; Accepted: 21.09.2018 \\ DOI: http://dx.doi.org/10.1590/0100-6045.2018.V41N4.JF
}

\section{Keywords:}

Autonomy

Practical reason

Aristotle

Kant

Ethics

Abstract: The perennial appeal of Kantian ethics surely lies in its conception of autonomy. Kantianism tells us that the good life is fundamentally about acting in accordance with an internal rather than an external authority: a good will is simply a will in agreement with its own rational, self-constituting law. In this

${ }^{1}$ I am grateful to audiences at The University of Chicago, Yonsei University, Universität Leipzig, and the St. Louis Annual Conference on Reasons and Rationality for feedback that has helped advance the arguments of this paper. Special thanks are also owed to Sergio Tenenbaum and Wolfram Gobsch, whose insightful criticisms have helped me think through these issues more clearly. 
paper, I argue against Kantian autonomy, on the grounds that it excessively narrows our concept of the good, it confuses the difference between practical and theoretical modes of knowing the good, and it cannot respect the essential efficacy of the principles of practical reason.

The perennial appeal of Kantian ethics surely lies in its conception of autonomy. Kantianism purports to give us an account of the good life as fully autonomous--i.e., in accordance with norms that are in principle accessible to all finite agents with the capacity to act from sources found in pure practical reason. Kantianism tells us that the good life does not consist in our obedience to any external authority; the Kantian imperative of morality simply tells us that we must act in accordance with the principle that constitutes our very own capacity to reflect, deliberate, and judge practically in the first place. The authority of morality is a purely rational authority, and we find its source within ourselves. A Kantian good will, then, is simply a will in agreement with itself-i.e., with its own internal, selfconstituting law.

The appeal of this conception of rational autonomy is straightforward. First, it promises to demonstrate that morality is objective and universally binding, while also accounting for its potential to motivate the will to act. Second, it appears to silence the moral skeptic, because it locates the source of moral normativity in the conditions of the possibility of acting at all, a project we are all inescapably engaged in. Third, it purports to show that principles of practical reason are just as formal and universally binding as its more well-established theoretical counterparts. Finally, it presents us with a philosophical ground for a flattering self-image of the species as (at least potentially) free to determine our own lives apart from step-motherly nature. If the Kantian conception of rational autonomy is true, then we are justified in 
continuing to take ourselves to be far more than what biology and social science tell us we are: that is, more than just a contingently determined animal form of life, whose choices and ends are shaped in large part by powerful evolutionary and social-historical forces we neither rationally designed nor endorsed. And we can do this without having to appeal to an intelligent creator who made us to occupy a certain exalted position in the intelligible order of creation. For, according to Kantianism, it doesn't matter what theology or science could tell us about human nature. From within the practical perspective of choice and action, that is, the perspective of the acting person faced with the task of making choices, here and now, we are essentially reflective, self-critical agents who have the capacity to constitute our own existence in accordance with laws of pure practical reason. Moreover, such laws are known from within (and only from within) this perspective. Kantian autonomy effectively seals off practical reason and value from both the dogmatic claims of metaphysics and theology and the empirical realm of nature, in order to preserve an intrinsically practical, a priori space in which freedom and morality can still be plausibly vindicated.

Kantian autonomy can and has been attacked on many different grounds. Many of these critiques, however, depend on empiricist sensibilities and intuitions that merely beg the basic questions at stake. This paper will attempt to critique the Kantian position without relying upon controversial assumptions the Kantian will not accept. My basic complaint in this paper is that what Kantians say about the "rational concept good" and "pure practical reason" is inconsistent with other claims they make about the efficacious causality of reason in its practical mode. If we pay close attention to these tensions within the Kantian framework, we begin to see that the very idea of a "pure practical reason" is a self-contradictory concept; it will fail to have an extension in any possible world. These 
confusions can, in the end, be traced to a deep misunderstanding of the grammar of goodness in general. The central objection is that Kantians model practical rationality too closely on its theoretical counterpart, thereby obscuring the genuine differences between them. I conclude that, much like the dogmatic rationalists they so often chastise, the Kantian's attempts to explain how the will can be genuinely rational-i.e., universal, formal, and objectively valid as reason or knowledge-makes it impossible for them to show it can be genuinely practical as the efficacious cause of its own objects.

\section{KANTIAN AUTONOMY}

First, let us get clearer about the target. In this paper I am not engaged in the project of understanding Kant's texts, but rather, how Kant's texts have been put to use and interpreted by contemporary theorists who seek to move the Kantian project forward. Whether this neo-Kantian movement is faithful to Kant's texts is a separate and interesting question I will not engage. ${ }^{2}$

At the heart of Kantian autonomy is a certain conception of the will as "nothing other than practical reason." (G 412) Kant's definition of will contains two, essentially connected claims. First, that the will is a rational capacity and therefore is a self-determined, self-consciously reflective and critical capacity whose proper exercise yields universally valid reasons for action. Second, that the will is

2 I am grateful to Wolfram Gobsch for pressing me to narrow down my target to contemporary neo-Kantians. I am inclined to agree with him that Kant has resources in his own theory, such as the practical postulates that require belief in God and immortality, and the doctrine of the highest good, that would at least blunt the force of many of the objections raised here. 
a practical capacity and so is essentially such as to produce the objects it cognizes. I will address these two features of the will-its autonomy and its efficacy-in order to argue that there is a deep and irreconcilable tension between them.

\section{The Will as Capacity for Reason or Knowledge 3}

As a rational capacity, Kant argued that the will must be a self-conscious, self-determined capacity for practical judgment that, when exercised properly, is grounded in reasons and yields a kind of knowledge. ${ }^{4} \mathrm{~A}$ reason, as the justifying ground of knowledge, must be universally valid and self-consciously so.

3 The presentation of ideas in this section is greatly influenced by Stephen Engstrom's interpretation of Kant's practical philosophy in his recent book, The Form of Practical Knowledge, Cambridge MA: Harvard University Press, 2009.

${ }^{4}$ For the purposes of this paper, I will assume that those who think that practical reason yields universally valid and objective reasons also think that these reasons are the grounds of a special kind of practical knowledge, since it's difficult to understand the concept of a reason as that which justifies apart from the concept of knowledge (at least as Kant understands it). In this respect, I follow Engstrom, who also self-consciously departs from John Rawls's famous turn away from an epistemological reading of Kant's practical philosophy. But whether or not any particular Kantian wishes to speak of practical knowledge explicitly, insofar as one speaks of practical reasons and judgments as universally valid, public, communicable, self-conscious, and systematic, one seems to be speaking about considerations that justify what Kant called "common moral rational knowledge" throughout his practical philosophy. At any rate, nothing in my argument hangs on my use of this terminology. One can substitute in "decision" or "judgment" for every place I use the word knowledge, and all the arguments will go through just the same.

Manuscrito - Rev. Int. Fil. Campinas, v. 41, n. 4, pp. 159-193, Oct-Dec. 2018. 
Let us begin with the universality requirement on reasons. Reasons are universal and essentially communicable; thus, even when it's not shared with anyone else, grasping a reason as the ground of judgment or decision is no merely private achievement. ${ }^{5}$ For instance, if I know that $p$, then the reasons I cite in favor of $p$ will be reasons that anyone else with the same capacity for knowledge can recognize as a legitimate ground for thinking that $p$ is true. The concept of knowledge, insofar as it is tied to justification and truth, depends upon this kind of universality. ${ }^{6}$

Implicit in the universality requirement is the idea that the subject of a rational cognition has a self-conscious recognition that agreement about its object is possible. This idea of possible agreement reached by different subjects is a condition of the possibility of judging at all, and again reflects the essential communicability of knowledge. We gain knowledge through the process of asking for, giving, and taking reasons from each other. No one gives or takes a reason from another if she does not have some implicit, self-conscious recognition that the reason holds good for others beside herself; reasons are considerations that constitute the common currency of intersubjective, rational discourse, which could not exist in absence of publicly accessible standards.

So, to act for a reason is to act on the basis of considerations that one self-consciously recognizes "would be valid for anyone in similar circumstances." (Velleman, 2006 , p. 20). To act against reason violates this requirement, because it is to act for a reason in which self-consciousness of potential agreement is wholly lacking. David J. Velleman

5 This is why Korsgaard (1996) compares the impossibility of private reason with the impossibility of a private language.

6 "If a consideration counts as a reason, then it counts as a reason whenever it is true.” J. David Velleman (2006), p. 21. 
brings this out nicely in his characterization of the morally problematic character of the act of lying:

If we lie, we hope that others will believe what we say even though we don't believe it, as if what we say should count as a reason for them but not for us. Once again, we attempt to separate reasons for us from reasons for others. In doing so, we violate the very concept of a reason, which requires that a reason for one be a reason for all (2006, p. 20).

Acting immorally violates the concept of a reason, Velleman argues, because such a reason cannot lead to "common knowledge among all reasoners" (2006, p. 29). And Kantians are quick to point out that bad action is often done for a "private" or "particular" reason, one that the actor does not recognize as universally valid for others.

Second, reason is characterized by its "spontaneity": it is an essentially self-determined and active, rather than receptive and passive power. ${ }^{7}$ Let us call this the spontaneity requirement. Acts such as judgments and choice are typically characterized as spontaneous, which means that they do not arise unbidden in us, like pains, itches, or feelings of sorrow, nor are they activities that merely happen within us sub-personally, like digestion or circulation. Making a judgment or choice is something I do because of some ground I have for doing it; when I judge that $p$ or decide to $\varphi$, I necessarily take myself to have

\footnotetext{
7 "Reasoning is self-conscious, self-directing activity through which we deliberately give shape to the inputs of receptivity. This happens both in the case of theoretical reasoning, when we are constructing a scientific account of the world, and in the case of practical reasoning, where its characteristic manifestation is choice" (Korsgaard, 2009) p. 207.
} 
reasons to do so, and these reasons are an expression of my first personal authority or spontaneity. ${ }^{8}$

As previously mentioned, I must also be selfconsciously aware of the reasons as universally valid or justified in order to judge. A self-conscious form of agency is one that does not merely act on its "incentives" or "inclinations," but which makes something like an all things considered judgment grounded in principles. ${ }^{9}$ An agent would not be truly self-determined or active if she were merely pushed about by her desires, as leaves are blown about by the wind. And so, Christine Korsgaard argues that:

Cut loose from the control of instinct, we must formulate principles that will tell us how to deal with the incentives we experience. And the experience of decision or choice, the work of these principles, is a separate experience from that of the workings of the incentive itself (2009, p. 119).

${ }^{8}$ For the classic statement of this, see Richard Moran (2001) and (2002).

${ }^{9}$ For the sake of clarity and in order to present it in the most charitable light, I will try not to tie my discussion of the Kantian conception of practical reason too closely to Kant's idiosyncratic moral psychology of incentives and inclinations. It seems necessary to replace this foreign vocabulary with the more familiar language of desire (in full awareness that we can usefully contrast sensible and rational desires-i.e., those desires that come from the operations of our senses and those that come about through judgment and deliberation-and that Kant isn't thinking of desire in the contemporary sense of a propositional attitude). 
In this passage, Korsgaard argues that for us to be the authors of our own actions, we need to have principles that can help us transform mere desires into reasons for acting. Only a self-conscious agent needs principles of reason, because only a self-conscious agent can identify herselfher rational agency - as someone over and above the play of sensible desires she experiences within her, someone faced with the task of deciding amongst their competing claims.

In short, the self-conscious character of reason opens up a space of reflective distance between the agent and her self-conscious desiderative states. This reflective distance creates a problem for an agent-what Korsgaard has called the normative problem-which is the task of finding a reason or justification for the desire for one object over another. ${ }^{10}$ This reflective distance creates a problem for agents, what Christine Korsgaard calls the normative problem, which is the task of finding a reason in favor of pursuing one object of desire over another.

Happily, the will (or what is supposed to be the same, practical reason) supplies its own purely formal, constitutive measure of good operation. This is the "law of a free will," or the categorical imperative, which is characterized as "the form of the rational will." As this imperative or principle is formal, it simply tells us that whatever the content of our individual maxims, they must all bear the form of a law-i.e., they must be universally valid as reasons - in order to be moral. As Korsgaard explains:

The categorical imperative merely tells us to choose a law. Its only constraint on our choice is that it have the form of a law. And

${ }^{10}$ This is not to say that reason simply chooses between already existing, competing desires. Through reflection (and presumably imagination) a rational agent can also form novel desires. 
nothing determines what the law must be. All that is has to be is a law. Kant concludes that the categorical imperative just is the law of a free will. It does not impose any external constraint on the free will's activities, but simply arises from the nature of the will. It describes what a free will must do in order to be a free will. It must choose a maxim that it can regard as a law (2008, p. 320).

The categorical imperative tells us what it means to "have the form of a law." We have already seen that reasons must be universal in the sense that they contribute to common knowledge. But we have not yet said how this common knowledge or framework is determined-i.e., how rational agents can judge whether their maxims have "the form of a law."

Stephen Engstrom offers a helpful account. Engstrom points out that Kant understands the universal validity of practical judgment in two senses, subjective and objective. ${ }^{11}$ Subjective universal validity of judgment is the implicit selfconscious understanding that it is possible for any subject with the capacity to judge to recognize that every finite rational being, in the same conditions, could agree to act in the way determined by the object of the judgment. Objective universal validity, by contrast, is the implicit selfconscious awareness that any possible object to which the concept can be applied, when in the very same conditions of the object judged, could have its predicate asserted of it. A practical reason must ground both types of selfconscious validity; that is, the subject must recognize that every rational agent could share the judgment, and that any object to which the concept is applied could share the same

${ }^{11}$ Engstrom (2009), p. 115-18. 
predicate. ${ }^{12}$ This sense of double universal validity gives a specific meaning to the injunction that, "when you will your maxim as a universal law, you must will it as a law for every rational being" (Korsgaard, 2009, p.80)

I do not here wish to enter into the on-going debates about how to interpret the categorical imperative test Kant outlines in the Groundwork, or how to square the three formulations of the categorical imperative with one another. It is enough for our purposes to acknowledge that, however we parse it, a maxim is good when it can be willed universally for all finite rational beings, and this universality speaks to its validity as a practical judgment, it's validity as a potential ground of knowledge which is essentially communicable to all agents with the capacity to know.

However we cash out what it means for a maxim to be "willed as a universal law," the main point here is that practical reasons must be formally valid in some sense suitably captured by Kant's formal practical principle and this sense must spell out its formal validity as a practical judgment that holds equally for all finite rational beings with the capacity to judge. This formal validity of practical judgment will spell out the contributions of "pure practical reason" to choice and action; it will be an account of the pure practical principles internal to the proper functioning of any finite rational will. The internal law of the rational will must be formal if it is pure, or truly autonomous in the Kantian sense.

\footnotetext{
${ }^{12}$ See Engstrom on the connection between validity in practical judgment and knowledge. He writes that "the form of willing is just the form of willing's own validity as knowledge, and since this form can determine the will's excise so that the content agrees with itself, this form can be described as a principle of selfagreement, a principle of unity or identity." (2009), p. 133.
} 


\section{The Will As a Practical Capacity}

On the Kantian view, the will is not simply a capacity for reasons or knowledge but a capacity for practical reasons or knowledge. What makes the will a practical capacity is that it is productive of the very objects it cognizes. It is, according to Kant's own definition, "a kind of causality that living beings have insofar as they are rational” (G 446). Or, as Thomas Hill puts the point in more contemporary terms, it is a capacity "to make things happen intentionally and for reasons" (2013, p. 18).

Now, practical judgment does not determine its objects as true, because it does not register what is, but what ought to be. Thus it is a judgment that something is good in a distinctively practical sense. Such judgments are productive because they do not simply determine a good, but produce what is so determined - i.e., the agent, in judging, works to bring into existence the object of its judgment. Let us call this the efficacy requirement on practical judgment.

Unlike the universality and spontaneity requirements, the efficacy requirement holds only for thought and reason in its specifically practical or productive mode. Only practical reason both determines and brings its object into being. Objects of theoretical judgment are given from elsewhere, through the senses; objects of practical judgment, by contrast, are determined through the use of reason. An object of practical judgment is completely determined from principles and brought into being by the subject who cognizes it. Practical judgment is self-determination par excellence.

Now, if the will is a rational, self-conscious causality that explains at least some actions that take place in the world, then any account of its exercise must contain, in addition to its self-consciousness of objective and subjective validity as judgment, an implicit self-consciousness of its own efficacious power to produce the object it has rationally 
determined 'ought to be done' or 'is good.' A judgment could not be practical if its lacked this essential selfconscious awareness of its efficacy, and thus a practically rational self-consciousness must be a consciousness of oneself as a rational causality - as the efficacious cause of change, both in oneself and in the world insofar as one acts in it. And this too is a difference with theoretical judgment or knowledge; in practical judgment, the subject judging and the object judged are one and the same, precisely because in practical judgment the object is determined by the subject. Engstrom writes:

$[\mathrm{P}]$ ractical knowledge distinguishes itself from theoretical in that its determination of its object-the good-must also be the practical determination of the judging subject. It reveals, that is to say, that the subject of practical knowledge is necessarily the same as the object this cognition determines (2009, p. 120).

In deciding to act, that is, in attaching a practical predicate to oneself as practical subject in practical thought, one "efficaciously specifies what one means to do" (2009, p. 33). ${ }^{13}$ This is a kind of self-determination or selfconstitution in a very strong sense, for in determining what one intends to do, one likewise determines the kind of person one is to be. In this way, the efficacy requirement on practical reason explains why practical judgment or

${ }^{13}$ Furthermore, Engstrom notes that "willing is self-consciously efficacious action specification." (2009, 45) For "if willing has no efficacy, the will could have neither strength nor weakness; and if the efficacy were not self-conscious, willing could not lie in any sort of thinking and hence could neither be nor be based in judgment or knowledge." 
choice is characterized as an act of self-determination or "self-constitution": in making practical judgments about what to do, an agent determines not only what happens in the world, but also, and even more importantly, the very kind of person she is. In short: we are what we will.

These two sides of rational willing-its universal validity as judgment and its causal efficacy as practical powercannot be comprehended independently of each other. So, we must say not only that, in acting rationally, one is selfconsciously aware that all finite rational beings would judge similarly about the object in question, but that one is also self-consciously aware that all finite rational beings have the efficacious power to determine or constitute themselves to realize what is so judged to be good, and thereby to determine their own form of existence. Self-determination and self-realization equally characterize the power of willit is an efficaciously autonomous rational power.

Kantian Autonomy

Now that we are clear about Kant's conception of rational will (or practical reason), we have all the pieces we need to articulate Kantian autonomy more precisely. According to Kantians, we are autonomous when we are fully self-determined agents; we are fully self-determined agents when we act in conformity with the formal principle that constitutes an exercise of the capacity to will (or practical reason); in so determining ourselves through our conception of the good, we are self-consciously aware of ourselves as the efficacious cause of what is objectively good for all finite rational beings who bear the same capacity.

Three aspects of Kantian autonomy are especially salient. First, the claim that the rational will is not essentially determined in any morally significant way by human nature, 
insofar as this is something distinct from what Kant calls "rational nature." Nothing about the particular kind of animal species bears upon practical principles of reasonNothing about our animality or the nature of our embodiment can bear upon the principles of pure practical reason. The worry about impurity is twofold: first, anything external to the will's own self-constituting law is obviously externally determined and therefore heteronomous or alien to it; second, what it is natural for human beings generally to need and desire qua human is fundamentally external or alien to the concept of the rational will, and can in no respect contribute to the principles that constitute good willing.

Second, Kantian autonomy takes it for granted that there is a practical perspective common to all finite rational beings, a perspective we share just in virtue of being autonomous agents who have the capacity to act for reasons. Without the possibility of such an idealized practical perspective, all this talk of the "subjective and objective validity" of practical judgment, or "practical laws" willed for all finite rational beings is just (highly suspect) metaphor. Kantian autonomy rests on the idea that the first person singular "I" of free choice is ultimately grounded in the first person plural or "we" of pure practical reason.

Moreover, this shared perspective amongst finite rational beings is supposed to be genuinely practical; it is supposed to set for us a formal end and good we must value supremely and can never (reasonably) act against or impede: the end of acting autonomously or freely or the value of rational nature as such. ${ }^{14}$ From this perspective, we can grasp the "essential interests" we have in common with all rational beings - the most obvious of which is the

\footnotetext{
14 See Barbara Herman (2007), p. 250 and Korsgaard (1996) and (2009).
} 
shared goal of becoming a person or a unified agent, a goal towards which we rational agents are inescapably oriented. ${ }^{15}$ David J. Velleman makes this requirement helpfully clear when he argues that, "rational creatures have access to a shared perspective, from which they not only see the same things but can also see the visibility of those things to all rational creatures" (2006, p. 25). This is the perspective the categorical imperative asks us to adopt, since it purports to test whether a reason for action can be, as Engstrom insists, "legislated by every person for every person." (2017, p. 50).

Third, Kantian autonomy is characterized by a commitment to formalism about practical principles and the good. This formalism has two parts. First, there is the idea that what is good or valuable is created by acts of will, and cannot exist independently of them. The practical good, insofar as it is materially substantive, is created through willing. The will just is the capacity to determine the concept of its object (the good) in conformity with its own form (the categorical imperative), and in so judging, bring this object into being. ${ }^{16}$ Second, the principles of practical reason must be formal in order to guarantee both their purity as principles of reason and their universal validity for all finite rational beings.

15 On our "essential interests" as rational agents, see Hill (2013), p. 20. For the idea that "being a person" is "something to which [we] unavoidably aspire" see Velleman (2006), p. 22 and for the idea that the goal of all agents is to become unified, see Korsgaard (2009), chapter 4.

16 For this characterization of autonomy as the capacity to determine or constitute one's own conception of life or existence, see Engstrom (2010), p. 134, and most recently, (2015). Or, as Korsgaard puts it, "the human is precisely the form of the animal that must create its own form" (2009), p. 130. 


\section{AgAinst Autonomy}

My arguments against autonomy will proceed from assumptions Kantians will accept. First, that practical reason is an essentially first personal or self-conscious power. Second, that we cannot understand 'acting for reasons" without bringing in some measure of justification and not mere explanation, and further, that any conception of justification depends upon some idea of universal principles. Third, that the good human life is the life of right practical reasoning or practical wisdom, and that practical thought and reasoning relate essentially to what is good or what ought to be done by human beings. Fourth, that practically rational action is reflective, self-determined, and free.

Of course, one needn't be a Kantian to believe these traditional claims about the good life and practical reason, or to think that the Kantian autonomous will is the best explanation of them. Tradition has long upheld these ideas without being committed to the idea that human beings are "autonomous" in the specifically Kantian sense. ${ }^{17}$

In what follows, I will argue that not only do we not need Kantian autonomy to defend these traditional claims, but that its adoption does positive harm to their broader credibility and acceptance. First, at the heart of Kantian autonomy is an excessively narrow and implausible account of good as a predicate. Second, Kantian autonomy does not respect the difference between our theoretical and our practical cognition of goodness. In fact, it makes goodness wholly a matter of practical reason. Third, it is not difficult

\footnotetext{
17 Aristotle, Augustine, Boethius, Anselm, and Aquinas, to name just a few. To read a concern with autonomy back into these authors is clearly anachronistic; more problematically, it robs Kant of some of his creative genius, making his philosophy far more derivative and traditional than it actually is.
} 
to show that the universality requirement and the efficacy requirement stand in irreconcilable tension with one another, and that the autonomy of practical reason does not sit well with its purported productivity. Although I treat them in concert, any one of these objections would suffice to bring Kantian autonomy into serious doubt.

\section{The Scope and Source of Goodness}

As we've seen, Kantians argue that 'good' is predicated by a subject as an object of specifically practical cognition, and therefore that 'good' is always determined by rational subjects out of such judgments. For something to be good is just for it to be (at least potentially) an object of will or practical reason. Therefore, the concept of the good must be, as Engstrom characterizes it, "wholly in conformity with that law of the will's autonomy" (2009, pp. 179-180). On this view, the good is determined through practical reason and cannot be understood apart from it.

As a claim about the grammar of goodness in general, this ought to strike us as deeply implausible-an unnecessary and unpalatable constriction of the economy of value. In fact, it states that we rational beings create the economy of value, which could not possibly exist in our absence. It rules out the idea that nature itself can be a source of value, which seems to contradict both ordinary judgment about nature and human experience of nature. More generally, judgments of goodness relative to a kind are not practical judgments; judgments of natural goodness do not make any claim about what I, qua subject of the judgment, ought to do or realize. ${ }^{18}$ These are not selfconstituting judgments in which subject and object are identical. Kantian autonomy rules out the possibility of

18 This is especially clear in Thomson (2008). 
such judgments, and is forced to explain them away because it is locked into a conception of goodness that is thoroughly moralized.

This brings us, I think, to the main problem with the Kantian enterprise: it attempts to find a single form of the good or the normative, a single mold in which all value or normativity can ultimately be said to fit. Let us call this the Platonic error about goodness. Surely Aristotle was correct to criticize Plato for not seeing that 'good' cannot be reduced to a single form or principle; for good is like health, what it is varies dramatically when attributed to different kinds of things. ${ }^{19}$

Now, to say that health varies dramatically when attributed to different kinds of things, is not to deny that there is a very general and abstract account of health-say, what it is for a body to function well as a whole or unitythat allows us to call a 'healthy' whale and a 'healthy' centipede both 'healthy' without total ambiguity of meaning. It is not an accident that we use the same term 'health' to refer to both, as it is a sheer accident that we call both the place I put my deposits and the terrain alongside a river 'bank.' The latter term is genuinely ambiguous; the former is not. But this general, abstract account of 'health' is normatively empty: it tells us nothing about what health is in a centipede as opposed to a whale; and it would be a huge mistake to think that health between the two creatures was basically the same, or that we adopt the same perspective of 'health' when we evaluate one as opposed to the other. This general scheme obviously does not provide a test of what is healthy in common between all things with a capacity for health. Predications of health display what the

${ }^{19}$ See EN I.6 1096a20-1097a14. Or, as Geach (1956) famously argues, good is an "attributive" rather than a "predicative" adjective. 
Aristotelian tradition calls an analogical unity. ${ }^{20}$ Good is not like "the white and the straight, which is everywhere the same" (EN VI.7, 1141a24-5).

However, all this is not to deny a special connection between practical reason and goodness; tradition has long upheld this. The trouble isn't the connection between goodness, will, and practical reason. The trouble is with Kantian autonomy, which is one way of understanding that connection, motivated by a desire for "purity". That is entirely absent from, and alien to, the traditional Aristotelian perspective.

Traditionally, practical reason was distinguished from theoretical reason by its end or aim: practical thought aims at realizing the good through action, whereas theoretical thought aims at knowing what is true. So, the work of practical thinking is not complete until what is objectively good is realized, and the work of theoretical thinking is not complete until objective truth is known. These different aims mark off very different types of thinking that require different cognitive skills or virtues; Aristotle thought it was obvious that one might be excellent at one type of thinking and quite terrible at the other. Each type of thinking has it's own 'wisdom' that pertains to each sphere; the theoretically wise man knows (or contemplates) the highest truths, and the practically wise man knows how to realize the highest good for a human and so lives a good human life.

Now, if the work of practical reason is to realize the good in material reality through action, then what constitutes the practical good (what Aristotle calls the prakton agathon) must be ends that are realizable by the very agents who cognize and desire them. Call this the realizability requirement on the practical good. This is an a priori constraint on the specifically practical good; it is best

${ }^{20}$ For an explanation of such unity, see Frey, C., Frey, J.A. (2017). 
thought of as a requirement on what it is for something to be an object of the will, rational desire, or practical judgment. For instance, I can judge that strong roots is good for an oak, or that thick fur is good for the polar bear, all the while not possessing the capacity to grow strong roots or thick fur myself. These are not goods that I can realize through my own activity, but they are goods for other living creatures all the same. When I speak of the practical good, by contrast, I have already constricted my thoughts to what it is possible for us human beings to realize, given the kind of creature we are. For if the efficacy requirement holds of practical reason and its principles-and Aristotle agrees with Kant that it must-that is, if it is essential to a practical cognition of the good that it be an efficacious and productive cognition, then the object of a practical cognition must be something that it is in the agent's own power to realize. Thus, the very recognition of an action or end as practically good is the recognition that it is to be realized by the very subject of the cognition: the agent herself (perhaps in cooperation with others).

Now, to be the efficacious cause of an action's coming to be, of an end or goal as being realized, is to do more than to cognize an object; to be the rational cause of an action is, in the very cognition of the object, also to move oneself so as to bring the object into being. In order to have such a productive cognition, a subject must have knowledge of what it is in general within her powers to bring about, and this involves knowledge of powers other than the will, such as the elementary bodily powers of locomotion and perception, as well as the ability to control the passions by various means. Our practical agency is largely the work of developing these other powers so that we can use them to pursue our ends, but the rational formation of our ends is also objectively constrained by what powers we have available to our use. One does not live well by intending alone; one lives well by realizing the 
good through one's own activity-by executing one's intentions successfully and realizing the good. But this activity involves powers that lie outside the will, powers that are part of our specifically human nature.

Aristotle affirms the importance of the realizability constraint at the outset of his discussion of the intellectual virtues (the virtues of thought) in the Nicomachean Ethics. He argues that we cannot deliberate practically about past events, the properties of triangles, or generally that which lies outside the voluntary domain of what we can bring about through the use of our own vital powers, of what can be pursued and avoided by us given the kind of agents we are. And the kind of agent we are is a human being, a certain kind of animal with certain powers, both active and passive. The perfection of these powers is the work of virtue, and virtuous activity is the stuff of 'living well for a human being', where 'living well' is the object, end, or goal of right practical reasoning.

This explains why Aristotle constricts practical wisdom or right practical reasoning to the practical good for mani.e., what human beings can and generally want to pursue as human beings, given their specifically human capacities for thought, action, and feeling. For Aristotle, the practical good for a man is what fulfills or completes these faculties in an integrated, holistic way-that which allows them to operate for the sake of the perfection of the whole.

The man who possesses practical wisdom, as opposed to theoretical wisdom, has "a true disposition accompanied by, relating to action in the sphere of what is good and bad for human beings" (EN VI.5, 1140b5-7).

In short, the practically wise man knows how to live well in a distinctively human way. Living well as a human being is his end, and this is a matter of both grasping and 
realizing distinctively human goods, like friendship, political society, and knowledge. These human goods are the essential constituents of the good life for a man, and thus are the necessary objects of the good human will.

Why doesn't Aristotle think that the practically wise man knows the good of rational life as such, the good as it pertains to all finite rational beings? After all, doesn't he say earlier in the same work that the "function" of human beings is the "life according to reason"? 21 To answer this question properly, we must tease out the full implications of the realizability requirement on objects of practical thought, and the specific ways in which it is opposed to formalism about practical reason and the good, and the idea that the rational subject of practical reason and knowledge is 'the finite rational being.'

Remember that the Aristotelian tradition distinguishes the two basic modes of thinking in terms of their distinct ends or constitutive aims: theoretical thought rests in the grasp of a true propositions about the way things are, and practical thought rests in the realization of some known end or good, through the exercise of human powers. Practical thought is productive of its objects, and so its work is not complete until the good has been fully realized. Because practical thought works to realize ends or goods, it is restricted to what can be realized through specifically human powers. If the will is truly a rational causality, a power to realize the objects of practical judgment, then an exercise of will must be identified with a certain kind of rational control or power: the power to do what reason judges one ought to do. Aristotle seems not to have a name for this, but the great Scholastic Aristotelian, St. Thomas Aquinas, does: he calls it our dominium, and he argued it extended to all that can be willed, or what is

${ }^{21}$ For a very Kantian reading of the function argument of EN I.7, see Korsgaard (2008), chapter 4. 
voluntary and he argues that it extends...22 Willing is the exercise of one's dominium, which extends all the way out into our causal interactions with things in the world, such as the lifting of a cup or the pushing of a chair. Our dominium is the vital power associated with the unimpeded exercise of the human will, or the capacity to "make things happen intentionally and for reasons." The very idea of the voluntary, of what can be an object of will, depends essentially on practical knowledge of what is within one's power as an agent to realize.

The thought here is relatively simply. What practical reason judges you ought to do, and what the will can realize is constrained by what you can do, given the kind of creature you are. Acting rationally or willing is more than just intending or determining oneself to an end, it is also realizing the end or executing the intention. Moreover, executing intentions is more than a matter of will: it is a matter of the exercise of many of my other powers: perception, locomotion, memory, imagination, and so on. The kind of animal I am limits the kind of action concepts I can predicate to myself in acts of practical thought, and thus the kind of ends that I can and want to pursue or avoid. In short, my animality constrains the intelligible outer limits of my practical thought and action.

It is the realizability requirement, then, that explains why Aristotle thinks that practical reason, insofar as it picks out an efficacious, productive causality, would be different for man and fish. ${ }^{23}$ Having introduced a distinction between phronesis and sophia, Aristotle writes:

${ }^{22}$ See Aquinas, ST I-II, Q6. I think though, it is reasonably clear from Aristotle's discussions of the voluntary that he is also working with something like a conception of dominium. For a nice discussion, see Flannery (2013), chapters 3-4.

${ }^{23}$ Aquinas agrees with Aristotle about human good being the proper object of practical wisdom. ST II-II 47.2.1 
Now if healthy and good are different for human beings and for fish, while white and straight are always the same, everyone will agree that what is scientifically known too, is always the same thing, whereas what is practically wise differs; for each kind of creature asserts that what is wise is what successfully considers the things relating to itself and will hand over decisions to that (EN VI.7, 1141a20-27).

Aristotle's thought here seems to be that if a fish attained sophia or theoretical wisdom-say, the truths about logic, mathematics, and other things eternal and unchanging-it would be the same as what a man could attain. The fact that $2+2=4$ is not a truth relative to human beings, but perhaps the fact that it is good for a man to have friends is. This is because practical wisdom does not track eternal truths, but realizes the good, and the good is different for man and fish. Of practical wisdom, Aristotle writes,

"There will not be one, dealing with the good of all kinds of creatures, but a different one for each." To think otherwise would be as ridiculous as to think there could be "a single form of medical expertise appropriate to every kind of being."

(EN, VI.5, 1141a32-4)

It would be to forget that 'good' and 'health' are not at all like the 'white' and 'straight'-always and everywhere the same. Aristotle concludes:

It is [practical] wisdom [phronesis] that has to do with things human, and with things one 
can deliberate about; for this is what we say is most of all the function of the wise person, to deliberate well, and no one deliberates about things that are incapable of being otherwise, or about the sorts of things that do not lead to some end, where this a practicable good. And the person who is without qualification the good deliberator is the one whose calculations make him good at hitting upon what is best for a human being among practicable goods (EN VI.7, 1141b9-13).

The practically wise man, or the virtuous man, knows how to deliberate about what is best for a human being or what makes for a good human life. He does not know what is good for all rational beings in general, for the simple reason that he does not necessarily have their capacities or participate in their form of life or share ends in common. He is, quite literally, not in a position to judge what they would find worthy of pursuit. ${ }^{24}$ Aristotle holds out the possibility that there may be different rational animals with different characteristic capacities and ends, and therefore different desires and goods. What it is reasonable and good for a man to do might be totally different from what it is reasonable for a rational fish in some distant galaxy to do. To think that practical reason is as cosmically universal as theoretical reason is, once again, to commit a kind of Platonic error about the good: it is to think that what is 'morally good' can be explained in terms of one and the same form. It is this kind of single form that the Kantian seeks when she speaks of the form of a maxim in general, or the form of practical knowledge.

${ }^{24}$ Even should he become acquainted with this other kind of creature, he would only be in a position to make theoretical judgments about its good, in the way that we make judgments about the good of an oak. 
It is the divorce between practical reason, willing, and human nature that is the problem from the traditional Aristotelian perspective. For the Aristotelian, the will is a power of a human being that, like all human powers, comes to be and operates for the sake of a single, unifying end: living well, or human form. This end cannot be spelled out independently of the virtues, since virtuous activity constitutes what it means to live well, and the virtues are those dispositions of thought, action, and feeling that perfect our specifically human powers. For instance, courage wouldn't be constitutive of living well for a human being if we didn't feel fear. Finally, it makes no sense to speak of an end we are all pursuing outside the framework of powers necessary to pursue ends generally. This runs afoul of the realizability requirement on the practical good.

What we see when we tease out the implications of the realizability requirement, is that the universal, self-legislating character of Kantian practical reason does not sit well with its claims to be an efficacious or productive power. Kantians demand that practical principles be both universally self-legislating (or self-consciously universally valid for all finite rational beings) and practically efficacious (or the productive cause of what it cognizes). What I am suggesting is that no mere "form of the good" could serve both roles simultaneously. We cannot possibly know a priori what other rational beings can realize through the use of their own powers, and thus what they can cognize as goods to be pursued and realized, and so we cannot possibly say that what we cognize as good is something they can cognize as good. Moreover, the realizability constraint casts doubt on the idea that we can isolate formal principles of good deliberation in abstraction from any conception of the kind of the kind of living thing in question.

For instance, imagine that we come upon a rational, alien form of rational life that reproduces itself asexually 
(perhaps it simply clones itself naturally). It is almost impossible to imagine that the goods unique to family life will be practically cognized by such creatures (goods that include spousal love and love for children). Such creatures surely have no capacity to feel familial or spousal love, as they have no need or desire for family. After all, such a creature does not have a mother or father, aunts, uncles, or cousins, which are categories that depend on a certain way a species reproduces itself. Such things are absent from its self-replicating, radically independent form of life. To insist that such creatures must have some desire to pursue committed love to another person or to intimate bodily companionship in general, or to think that they will form families, political societies, or deep friendships is to anthropomorphize them without reason; these things are so with us, but not necessarily so for other rational creatures, with different emotional capacities and bodily needs. Our lives may be irreconcilably different, our goods incommensurate. It may be impossible for different forms of rational animality to relate to one another in such a way as to share forms of life, let alone attempt to build a "Kingdom of Ends" together 25 ."

These thoughts call into question another key assumption of Kantian autonomy, that there is a perspective of pure practical reason that all rational beings

${ }^{25}$ It doesn't help matters to point out that Kant thinks that the more determinate content of our duties does depend on human nature, and that this is spelled out clearly in the Doctrine of Virtue. The complaint isn't that Kant doesn't let in our animality at all; the complaint is that he brings it in too late. The problem is that an account of practical reason that relegates our animality to a second-class, "impure" status, is an account that fails to be practical in any meaningful sense. Such an account assumes a practical perspective that floats free of the most general conditions for realizing itself. The argument given here is that there can be no such perspective that is genuinely practical. 
can adopt, as bare "finite rational agents." It is understandable that Kantians want to find such a perspective, since it would make practical thought very much like its more familiar theoretical counterpart. It would make the perspective of pure practical reason just as universal and binding as the perspective of theoretical reason; objective and subjective universal validity would indeed hold equally for both. David J. Velleman brings out the analogy clearly when he writes:

Anyone who adds 2 and 2 sees, not just that the sum is 4 , but also that anyone who added 2 and 2 would see that it's 4 , and that such a person would see this too, and so on. The facts of elementary arithmetic are thus common knowledge among all reasoners, in the sense that every reasoner knows them, and knows that every reasoner knows them, and so on...This shared perspective is like a vantage point overlooking the individual perspectives of reasoners, a standpoint from which we not only see what everyone sees but also see everyone seeing it. And once we glimpse the availability of this vantage point, we cannot help but aspire to attain it (2006, p. 25).

All rational subjects can judge that $2+2=4$ because this is objectively true. According to Velleman, practical reasoning is genuinely reasoning, then surely the same must be true of its judgments, all rational beings must be able and ought to affirm them.

This models practical reason too closely on theoretical reason, and it does not respect the specific character of the practical good. Practical thought does not aim at truth alone, but the realization of what is good. But again, what 
is truly good shifts from species to species, in large part because what can be desired, pursued, and realized shifts from species to species. The perspective of pure practical reason does not respect this fact, and for that reason it is not truly a practical perspective that concerns what can be pursued and realized at all. The idea of a categorical imperative as a law given by pure reason is the idea of a form of goodness that is the same for all rational beings, a form of goodness that can be both acknowledged and efficaciously realized by them all. I have argued that such an idea is confused, and that this sort of practical autonomy is not possible. I cannot possibly have the self-conscious awareness of my practical judgments as objectively and subjectively valid for all finite rational beings, and thus I cannot will my maxims as laws that hold for all finite rational beings. I am in no epistemic position to judge what they can possibly realize or cognize practically as good, and so I cannot have the self-conscious awareness of the universality of my practical judgments in the sense stipulated by Kantian moral theory. If there is a perspective shared in common with all rational beings, it is surely not a practical one.

Another way to put the point I'm making is to say that no law of practical reason can be purely formal, because the idea of a formal law is incompatible with the idea of an efficacious, practical law. The Kantian insists that my flesh and blood humanity, my material animality, is irrelevant to the perspective of pure practical reason. Whatever pertains to my humanity is empirical, contingent, and therefore impure. ${ }^{26} \mathrm{I}$ am insisting, to the contrary, that matter matters to practical reasoning, even at the level of its most general

\footnotetext{
${ }^{26}$ For arguments that the concept human being is not empirical, see M. Thompson (2004) and (2008).
} 
principles. ${ }^{27}$ Practical principles, principles that regulate the formation of intentions, cannot be conceptually divorced from the conditions of their execution and remain practical in any meaningful sense. Call my view a practical hylomorphism in order to contrast it with Kantian formalism. This is why for Aristotle the first principles of practical reason (its arche or starting points) are human ends and goods, like knowledge and political society. I need the virtue of courage because I have certain ends and goods, and courage is necessary for me to attain them. But it is real human goods that demarcate the intelligible limits of practical reasoning, not "formal ends" or "principles." And notice that one does not find a single formal practical principle in Aristotle's philosophy. This is not an accident or a mere oversight on his part. He does not think they are possible.

At this stage in the argument, the Kantian might accuse me of failing to make the necessary distinction between Wille and Willkür, or wish and choice. The formal principles Kantians talk about are constitutive of willing, not of choosing. Our choices are good insofar as they conform with the norms of good willing in general, depends on empirical knowledge of what I can realize. The form of a maxim or practical knowledge only picks out that which all possible acts of practical cognition share in common. This must be logically prior to all possible content, and so it must be formal and common to all practical cognizers as the law that constitutes the act as an act of reason. What is naturally needful or pleasurable will be the "matter" on which practical reason operates, and that may well differ from species to species. But insofar as each species acts in the way that it good for it, it will be because their maxims conform to the form of practical

\footnotetext{
${ }^{27}$ For an account of practical principles that are conditioned by matter, see J.A. Frey (2018).
} 
cognition or knowledge in general, and this form will be the same for all practically rational beings.

While I understand that Kantians want to hold fast to a dualism between reason and human nature, my argument has been all along that this is a problematic position in tension with its own basic commitments. Insofar as the principles of Wille are supposed to be practical, they must meet both the universality and the efficacy requirement. And I have been arguing that it is impossible for it to meet the efficacy requirement and remain formal. So, Kantians face a choice: either give up the claim that the formal principles are genuinely practical, or give up the claim that they are formal. It is too great a concession for the Kantian to reply that their principles are only truly practical when "applied" to matter; this seems to treat them as if they are theoretical after all-i.e., not essentially productive or practical and self-consciously so.

\section{CONCLUSION}

In this paper, I have argued against the autonomy thesis, or the Kantian idea of universal self-legislation as the form of the good. Such an idea excessively narrows our conception of good, it confuses the difference between practical and theoretical modes of knowing the good, and it does not respect the essential efficacy of practical reason and its principles. Perhaps there are other, less "pure" notions of autonomy that are useful to moral and political philosophers. Nothing I have argued here indicates otherwise. 


\section{REFERENCES}

AQUINAS, T. Summa Theologiae [ST] Opera Omnia. Leonine Edition, 1882.

ARISTOTLE. Nicomachean Ethics [EN] Trans., by C. Lowe, Oxford: Oxford University Press, 2002.

AufderheIDE, J., BADER, R.M. The Highest Good in Aristotle \& Kant. Oxford: Oxford University Press, 2015.

Buss, S., Overton, E. Contours of Agency: Essays on Themes from Harry Frankfurt. Cambridge, Mass.: MIT Press, 2002.

Engstrom, S. The Form of Practical Knowledge. Cambridge, Mass.: Harvard University Press, 2009.

"Understanding Autonomy: Form and Content of Practical Knowledge” In E. Watkins (ed.) (2017), pp. 44-60.

"The Complete Object of Practical Knowledge." In J. Aufderheide and R. M. Bader (eds.) (2015), pp.129-157.

FlanNery, K. Action and Character According to Aristotle: The Logic of the Moral Life. Washington, D.C.: Catholic University of America Press, 2013.

Foot, P. Natural Goodness. Oxford: Oxford University Press, 2001.

FreY, C., FrEY, J.A. "G.E.M. Anscombe on the Analogical Unity of Intention in Perception and Action." Analytic Philosophy, 58, 3, 2017, pp. 202-247.

FreY, J.A. "How to be an Ethical Naturalist." In J. HackerWright (ed.) (2018), pp. 47-84.

GEACH, P. “Good and Evil.” Analysis, 7, pp. 32-42, 1956. 
HaCKeR-Wright, J. Philippa Foot on Goodness and Virtue. Palgrave macmillan, 2018.

Herman, B. Moral Literacy. Cambridge, Mass.: Harvard University Press, 2007.

HiLl, T.E. "Kantian Autonomy and Contemporary Ideas of Autonomy." In O. Sensen, (ed) (2013), pp. 15-31.

KANT, I. Grundlegung zur Metaphysik der Sitten, 1785 [G]. Trans. By M. Gregor and J. Timmermann, Cambridge: Cambridge University Press, 2012.

KORsgaARD, C. The Sources of Normativity. Cambridge: Cambridge University Press, 1996.

The Constitution of Agency. Oxford: Oxford University Press, 2008.

Self-Constitution: Agency, Identity, and Integrity. Oxford: Oxford University Press, 2009.

Macintyre, A. Dependent Rational Animals. Chicago: Open Court, 1999.

MORAn, R. Authority and Estrangement: An Essay on SelfKnowledge. Princeton: Princeton University Press, 2001.

"Frankfurt on Identification: Ambiguities of Activity in Mental Life.” In S. Buss., L. Overton, (eds.) (2002), pp. 189-217.

O’HEAR, A. Modern Moral Philosophy. Cambridge: Cambridge University Press, 2004.

Thomson, J.J. Normativity. Chicago: Open Court, 2008.

ThOMPSON, M. “Apprehending Human Form.” In A. O’Hear, (ed.) (2004), pp. 47-74.

Life and Action. Cambridge, Mass.: Harvard University Press, 2008. 
Velleman, D. Self to Self. Cambridge: Cambridge University Press, 2006.

Watkins, E. Kant on Persons and Agency. Cambridge: Cambridge University Press, 2017.

\section{(cc) $\mathrm{BY}$}

